\title{
HEALTH INEQUALITIES AMONG THE ELDERLY \\ IN WESTERN EUROPE
}

\author{
Silvia Rueda ${ }^{1}$ \\ Lucía Artazcoz ${ }^{2,3}$ \\ Vicenç Navarro ${ }^{1,4}$ \\ ${ }^{1}$ Universitat Pompeu Fabra, Barcelona, Spain \\ ${ }^{2}$ Agència de Salut Pública, Barcelona, Spain \\ ${ }^{3}$ CIBER en Epidemiología y Salud Pública, Spain \\ ${ }^{4}$ The Johns Hopkins University
}

Correspondence should be addressed to:

Silvia Rueda Pozo

Universitat Pompeu Fabra

Address for correspondence :

silvia.minimal@gmail.com

The Corresponding Author has the right to grant on behalf of all authors and does grant on behalf of all authors, an exclusive licence (or non exclusive for government employees) on a worldwide basis to the BMJ Publishing Group Ltd and its Licensees to permit this article (if accepted) to be published in JECH editions and any other BMJPGL products to exploit all subsidiary rights, as set out in our licence (http://jech.bmjjournals.com/ifora/licence.pdf)".

Keywords: gender, inequalities, elderly, socioeconomic factors, living arrangements.

Word count: 3449 in text; 252 in abstract; 50 references; 4 tables; no figures.

\section{ABSTRACT}


Background: This paper analyses gender inequalities in health status and in social determinants of health among the elderly in Western Europe.

Methods: Data came from the first wave of the "Survey of Health, Ageing and Retirement in Europe” (SHARE, 2004). For the purposes of this study a subsample of community-residing people aged 65-85 years with no paid work was selected (4218 men and 5007 women). Multiple logistic regression models separated by sex and adjusted for age and country were fitted.

Results: Women were more likely to report poor health status, limitations in mobility and poor mental health. Whereas in both sexes educational attainment was associated with the three health indicators, household income was only related to poor self-rated health among women. The relationship between living arrangements and health differed by gender and was primarily associated with poor mental health. In both sexes, not living with the partner but living with other people and being the household head was related to poor mental health status $(\mathrm{aOR}=2.14 ; 95 \% \mathrm{CI}=1.11-4.14$ for men and $\mathrm{aOR}=1.75 ; 95 \% \mathrm{CI}=1.12-2.72$ for women). Additionally, women living with their partner and other(s) and those living alone were more likely to report poor mental health status $(\mathrm{aOR}=1.67 ; 95 \% \mathrm{CI}=1.17-2.41$ and $\mathrm{aOR}=1.58$; 95\% CI=1.26-1.97, respectively).

Conclusions: Health inequalities persist among the elderly. Women have poorer health status than men and in both sexes the risk of poor health status increases among those with low educational attainment. Living arrangements are primarily associated with poor mental health status with patterns that differ by gender. 


\section{INTRODUCTION}

Over the last 50 years, the number of people aged 60 or over has tripled worldwide, and it is expected to more than triple again over the next 50 years. In 2030, Europeans of 75 years and over are expected to account for $12 \%$ of the population and those aged 80 years and over for 7\%. This "population explosion” has generated concern around the world related to health expenditure and the economic sustainability of national pension systems. However, little is known about health inequalities of this increasingly important segment of the population, nor about the social determinants of health, at least as compared with younger people [1][2].

Although research about social inequalities in health among elderly people has received less attention compared to that focused on other age groups, one of the most important conclusions is that socio-economic inequalities in health prevail in old age [3-13]. However, there are still many gaps in the research about social inequalities in health among the elderly that should be covered [14]. For example, there is no consensus about the best indicators of socio-economic position to be used among the elderly [15][16]. The Black Report suggested that at older ages classification by occupational class becomes less meaningful than among younger people [17]. Moreover, other researchers have proposed to use a set of complementary socio-economic status indicators among the elderly people [4].

A substantial and to some extent parallel literature, has shown that socio-demographic and social-psychological characteristics such as marital status and household living arrangements are also associated with health inequalities in older age groups. Reasons for these associations include both selection factors-good health increases the chances of marrying and remaining married for longer, for example — and the protective effects of care and support [18]. However, although marital status constitutes one of the most used indicators when analysing the health outcomes of individuals, it has been found that the association between marital status and mortality/morbidity is weaker among the elderly [18-21]. 
Household composition is considered to be one of the most basic and essential determinants of the well being of older adults [2][22]. Considerable interest has focused on whether living alone increases the risk for negative health outcomes among the elderly, but less attention has been paid to other types of living arrangements very common among them such as living with their adult children [23][24]. Additionally, like most studies about family characteristics and health, research focusing on living arrangements of the elderly is mostly centred on samples composed exclusively of women, assuming their traditional gender role as the person mainly responsible for domestic family tasks [24-27]. Yet, among retired elderly men, living arrangements and family characteristics could have a higher impact than among younger males and, additionally, given the domestic gender division of labour, the pattern of associations may be different to that among females.

The objective of this study is to identify gender differences in health status and to assess gender differences in the impact of socio-economic factors and living arrangements on health among the elderly in Western Europe.

\section{METHODS}

\section{Data}

Data came from the first wave of the "Survey of Health, Ageing and Retirement in Europe" (SHARE, 2004). SHARE is a multidisciplinary and transnational database collecting information about health, socio-economic position and family networks of about 22.000 persons above 50 years of age in ten continental European countries (Denmark, Sweden, Austria, France, Germany, Switzerland, the Netherlands, Spain, Italy and Greece). Although SHARE was designed from the outset as a longitudinal database, this paper analyses the only wave available at the moment, that is, wave 1. SHARE used design weights (calibrated weights), which were subsequently adjusted, to reflect the national populations [28]. For the 
purposes of this study a subsample of non-institutionalised people aged 65-85 years old who had no paid work was selected (4218 men and 5007 women). The minimum age has been chosen based on the standard retirement age for men in the majority of the countries under study [29], in an attempt to overcome certain limitations related to the inclusion of a mixture of people still in the labour market and those who have left it. The decision to take 85 years as the maximum age is based on fact that the weights in the database for the oldest-old may be less accurate [3]. The household response rate of the sample was $61.8 \%$ (weighted average).

\section{Dependent variables}

\section{Self-perceived health}

Self-perceived health status was elicited by asking the respondents to describe their general health as "very good”, “good”, “fair”, “poor”, or "very poor”. The variable was dichotomised by combining the categories "fair" and "poor" to indicate perceived health as below good. Self-perceived health is a broad indicator of health related well being and has also proved to be a good predictor of mortality [30][31].

\section{Mental health}

A dichotomous variable based on the EURO-D scale was constructed, taking the value 1 when the individual reported suffering at least three of the depressive symptoms shown in the card, and 0 otherwise. The EURO-D scale is an harmonized symptom scale developed to enhance the analysis of the pooled EURO-DEP data-set, necessary because not all the centres included in the original data-set used the same depression assessment procedure [32] [33]. To obtain a pooled data-set, the different instruments were harmonized and a 12-item scale was generated (see [34] for more information). As a result, the EURO-D scale is a subjective indicator of mental health composed of the following 12 items: depression, pessimism, 
suicidality, guilt, sleep, interest, irritability, appetite, fatigue, concentration, enjoyment and tearfulness. For each centre, the EURO-D has been shown to be internally consistent, with Cronbach $\alpha=0.72$ for the current pooled sample [35-37]. It has been reported that this scale is consistent and permits the establishment of valid comparisons [34][38].

Limitations in mobility (mobility, arm function and fine motor function)

The variable "health and activities", which enquires about people's possible difficulties in carrying out activities related to mobility due to health problems, was dichotomized in the SHARE database. The following activities were shown to the interviewed people: walking 100 metres; sitting for about two hours; getting up from a chair after sitting for long periods; climbing several flights of stairs without resting; climbing one flight of stairs without resting; stooping, kneeling or crouching; reaching or extending the arms above shoulder level; pulling or pushing large objects like a living room chair; lifting or carrying weights over 10 pounds/5 kilos, like a heavy bag or groceries and picking up a small coin from a table. The final variable equals 1 when the interviewed individual reported being affected by three or more limitations, and 0 otherwise.

\section{Independent variables}

Socio-economic position was measured through two indicators: educational attainment and household income. Although a high correlation between educational attainment and household income could be a limitation in this study, the correlation was not as high as anticipated $(\mathrm{r}=0.33)$. Therefore, both of them were included because they are measuring two different dimensions of the individuals’ socio-economic position.

Educational attainment was generated by following the original classification used in the SHARE questionnaire, the International Standard Classification of Education (ISCED97). Some categories of this classification were collapsed due to the low number of 
individuals in some groups. The final variable was made up of the following categories: no studies, primary education or less, secondary education, and higher than secondary education.

Household income was measured through the gross annual household income purchasing power parity (PPP)-adjusted, which includes the following income sources: income from other household members ppp-adjusted, other household benefits ppp-adjusted, rent value at household level ppp-adjusted, imputed rent value at household level pppadjusted, bank account at household level ppp-adjusted, government or corporate bonds at household level ppp-adjusted, stocks or shares at household level ppp-adjusted and mutual funds at household level ppp-adjusted. Due to the problem with missing data related to income variables which particularly affects elderly people, the SHARE database uses multiple imputations (MI), a technique that replaces each missing value with $M$ (in this case $M=5$ ) acceptable values representing a distribution of probabilities [39]. The income variable was divided by the square root of the number of people living in the household. Finally, the equivalized gross annual household income variable was introduced in the analysis as a categorical variable due to its asymmetrical shape.

The original 9-category household living arrangements variable hhtype ${ }^{1}$ was recoded into 5 new categories: living alone, living with the partner only (reference category), living with the partner and other people (one of the members of the couple is the household head), not living with the partner but living with other people and being the household head, and finally, not living with the partner but living with other people and not being the household head. Regarding the household heads, although SHARE does not specifically identify them, for the purposes of this study a proxy based on the household respondents of the questionnaires has been used. SHARE defines household respondents as "the person most

\footnotetext{
${ }^{1}$ Originally, hhtype included the following categories: single, couple, single with children, couple with younger children (0 to 17), couple with older children (18 and over), couple with young and old children, single or couple living with parent, three generation household and others. But due to the limited sample size and the household characteristics of the 65-85 years old people studied here, it has been decided to generate a typology with 5 categories more related to the population under study.
} 
capable of answering questions about the household members housing situation, household income, and family consumption questions .....” [40].

\section{Statistical analysis}

Multiple logistic regression models were fitted in order to calculate adjusted odds ratios (aOR) and 95\% confidence intervals (CI). Models were separated by sex, adjusted for age and weighted by using a calibrated individual weight for the main sample. Goodness of fit was obtained using the Hosmer Lemeshow test [41]. Additionally, to test for an independent linear trend between health outcomes and education and household income, logistic regression was performed fitting multivariate models including these predictor variables as continuous variables and the Wald test was used.

\section{RESULTS}

\section{General description of the population}

Table 1 shows a general description of the population under study. Men and women in the sample had a median of 72 years. Women were overrepresented in the lowest educational levels and income categories. Approximately $10 \%$ of women had not received a formal education and $35 \%$ had primary studies or less, compared to $7 \%$ and $32 \%$ of men, respectively. Moreover, the percentage of people belonging to the lowest income group was higher among females. Conversely, they were less likely to belong to the highest income group.

Regarding type of household, women were more likely to live alone (37\% vs. $14 \%$ ) whilst living with the partner was more frequent among men (72\% vs. 48\%). Finally, the 
percentage of those not living with the partner but living with other people (regardless of being the household head or not) was higher among women than among men.

Women were more likely to report poor health status, poor mental health and limitations in mobility, arm function and fine motor function. Whereas $15 \%$ of women had poor or very poor health, the percentage among men was $11 \%$. Moreover, the mean number of symptoms related to mental health problems and of limitations in mobility, arm function and fine motor function stated by women almost doubled those of men. 
Table 1. General description of the population (in percentages). Survey of Health, Ageing and Retirement in Europe, 2004.

\begin{tabular}{ccc}
\hline $\begin{array}{c}\text { Men } \\
(n=4218)\end{array}$ & $\begin{array}{c}\text { Women } \\
(n=5007)\end{array}$ & $p$ \\
\hline
\end{tabular}

Age (median, 25\%-75\% percentiles)

72, 68-77 $\quad 72,68-77 \quad<0.001$

Educational attainment

- Without formal education

6.5

$<0.001$

- Primary education or less

31.5

9.9

- Secondary education

43.2

34.5

- Higher than secondary education

17.9

44.5

9.8

Equivalized gross annual household income in $\mathrm{ppp}^{1}$

- Lowest $25 \%$

22.3

$<0.001$

- $25<50 \%$

31.2

32.2

- $50<75 \%$

26.5

30.7

- Top $25 \%$

19.9

22.1

14.9

Household living arrangements

- Living alone

$\begin{array}{cc}14.4 & 37.2 \\ 71.7 & 48.1 \\ 11.6 & 5.8 \\ 1.9 & 6.5 \\ & \\ 0.5 & 2.4\end{array}$

- Living with the partner

- Living with the partner and others

- Not living with the partner but living with others (household head)

- Not living with the partner but living with others (not household head)

Self-perceived health

- Very good

$\begin{array}{cc}13.2 & 9.2 \\ 41.3 & 38.0 \\ 33.9 & 37.7 \\ 8.9 & 12.1 \\ 2.5 & 2.9\end{array}$

Mental health (mean, 25\%-75\% percentiles) ${ }^{2}$

1.9, $0.0-3.0 \quad 2.9,1.0-4.0 \quad<0.001$

Limitations in mobility, arm function and fine motor

$1.4,0.0-2.0$

$2.4,0.0-4.0$

$<0.001$ function (mean, 25\%-75\% percentiles) ${ }^{3}$

${ }^{1}$ ppp means Purchasing Power Parity.

2 The indicator of mental health used here goes from 0 (not depressed) to 12 (very depressed), the original variable generated by SHARE.

${ }^{3}$ The indicator limitations in mobility, arm function and fine motor function used here goes from 0 (not limited) to 10 (very limited), the original variable generated by SHARE. 


\section{Gender differences in the determinants of health}

Prevalence of poor health outcomes was significantly higher among women for all three indicators. After adjusting for age, females were more likely to report poor self-perceived health status, poor mental health and limitations in mobility, arm function and fine motor function $(\mathrm{aOR}=1.30 ; 95 \% \mathrm{CI}=1.14-1.49 ; \mathrm{aOR}=2.47 ; 95 \% \mathrm{CI}=2.12-2.89$ and $\mathrm{aOR}=2.37 ; 95 \%$ CI=2.03-2.76, respectively). Gender differences remained after additionally adjusting for socio-economic indicators and country, although they decreased slightly for all three health outcomes (Table 2).

Table 2. Odds ratios (OR) and 95\% confidence intervals (CI) comparing health outcomes of women to men (reference category). Survey of Health, Ageing and Retirement in Europe, 2004.

aOR (95\% CI)

Poor self-perceived health

- Adjusted for age

- Adjusted for age, country and socio-economic position

Poor mental health status

- Adjusted for age

$2.47(2.12-2.89)^{* * *}$

- Adjusted for age, country and socio-economic position

Limitations in mobility, arm function and fine motor function

- Adjusted for age

- Adjusted for age, country and socio-economic position $2.23(1.90-2.62)^{* * *}$

${ }^{*} \mathrm{p}<0.05$; ** $\mathrm{p}<0.01$; *** $\mathrm{p}<0.001$ 
In both sexes, an association between educational attainment and poor health outcomes was observed and a consistent gradient was found. People without a formal education had the highest probability of reporting poor health compared to those with higher educational attainments. No such consistency was found for household income. Only among women was a positive relationship for poor self-rated health found in the lowest income category (Tables 3 and 4).

The association between household living arrangements and health differed by sex and the health indicator analysed. They were primarily related to poor mental health status but no association was found for self-rated health status in either sex and only a positive association with limitations in mobility was observed among women living with the partner and others (aOR=1.45; 95\% CI=1.01-2.08). In both sexes, mental health was poorer among people not living with the partner but living with others and being the household head (aOR=2.14; 95\% $\mathrm{CI}=1.11-4.14$ for men and $\mathrm{aOR}=1.75$; $95 \% \mathrm{CI}=1.12-2.72$ for women). Among men, a positive association with poor mental health status was also found among those not living with the partner but living with other people and not being the household head (aOR=3.47; 95\% CI=1.15-10.49). Additionally, females living with their partner and other people and those living alone were more likely to report poor mental health status (aOR=1.67; 95\% CI=1.172.41 and $\mathrm{aOR}=1.58 ; 95 \% \mathrm{CI}=1.26-1.97$, respectively). Although not included here because of shortage of space, the results of interacting household living arrangements and sex were also statistically significant in their associations with poor mental health for living with a partner and others and also for living with others and not being household head. 
Table 3. Multivariate associations between the dependent variables and the socio-economic and household living arrangements indicators.

Men 65-85 years old. Adjusted odds ratios (aOR) and 95\% confidence intervals (CI). Survey of Health, Ageing and Retirement in Europe, 2004.

\begin{tabular}{|c|c|c|c|c|c|c|}
\hline & \multicolumn{2}{|c|}{ Poor self-perceived health status } & \multicolumn{2}{|r|}{ Poor mental health } & \multicolumn{2}{|c|}{ Limitations in mobility } \\
\hline & $\%$ & aOR (95\%CI) & $\%$ & aOR (95\%CI) & $\%$ & aOR (95\%CI) \\
\hline $\begin{array}{ll}\text { Educational attainment } \\
\text { - } & \text { Higher than secondary } \\
\text { - } & \text { Secondary } \\
\text { - } & \text { Primary or less } \\
\text { - } & \text { Without formal education }\end{array}$ & $\begin{array}{l}33.6 \\
43.1 \\
51.5 \\
62.8\end{array}$ & $\begin{array}{l}1 \text { †† } \\
1.48(1.08-2.03)^{*} \\
2.38(1.60-3.54)^{* * *} \\
3.31(2.03-5.39)^{* * *}\end{array}$ & $\begin{array}{l}12.2 \\
15.2 \\
21.6 \\
35.4\end{array}$ & $\begin{array}{l}1 \text { ††† } \\
1.54(1.02-2.31)^{*} \\
2.06(1.30-3.24)^{* *} \\
3.49(1.96-6.21)^{* * *}\end{array}$ & $\begin{array}{l}14.4 \\
16.7 \\
25.8 \\
36.7\end{array}$ & $\begin{array}{l}1 \text { ††† } \\
1.58(1.06-2.35)^{*} \\
3.09(1.90-5.05)^{* * *} \\
3.99(2.19-7.27)^{* * *}\end{array}$ \\
\hline $\begin{array}{l}\text { Equivalized gross annual } \\
\text { household income in ppp } \\
\text { - } \quad \text { Top } 25 \% \\
\text { (reference category) } \\
\text { - } \quad 50 \%<75 \% \\
\text { - } \quad 25 \%<50 \% \\
\text { - } \quad \text { Lowest } 25 \%\end{array}$ & $\begin{array}{l}35.4 \\
42.8 \\
47.1 \\
54.9\end{array}$ & $\begin{array}{l}1 \dagger \\
1.10(0.79-1.54) \\
1.18(0.84-1.65) \\
1.41(0.97-2.06)\end{array}$ & $\begin{array}{l}15.8 \\
15.0 \\
18.2 \\
23.1\end{array}$ & $\begin{array}{l}1 \\
0.82(0.55-1.22) \\
1.02(0.64-1.64) \\
0.97(0.64-1.47)\end{array}$ & $\begin{array}{l}15.0 \\
17.5 \\
20.7 \\
28.8\end{array}$ & $\begin{array}{l}1 \\
0.80(0.53-1.22) \\
0.86(0.59-1.27) \\
1.07(0.70-1.63)\end{array}$ \\
\hline $\begin{array}{l}\text { Household living arrangements } \\
\text { - } \quad \begin{array}{l}\text { Living with the partner } \\
\text { (reference category) }\end{array} \\
\text { - } \quad \text { Living alone } \\
\text { - } \quad \text { Living with the partner and } \\
\text { others } \\
\text { - Not living with the partner but } \\
\text { living with others (household } \\
\text { head) } \\
\text { - Not living with the partner but } \\
\text { living with others (not } \\
\text { household head) }\end{array}$ & $\begin{array}{l}45.0 \\
43.1\end{array}$ & $\begin{array}{l}1 \\
0.89(0.65-1.22)\end{array}$ & $\begin{array}{l}16.4 \\
21.3\end{array}$ & $\begin{array}{l}1 \\
1.12(0.77-1.63) \\
1.21(0.85-1.73)\end{array}$ & $\begin{array}{l}19.1 \\
23.5\end{array}$ & $\begin{array}{l}1 \\
1.17(0.81-1.67)\end{array}$ \\
\hline
\end{tabular}

${ }^{*} \mathrm{p}<0.05 ;{ }^{* *} \mathrm{p}<0.01 ;{ }^{* * *} \mathrm{p}<0.001 ; \dagger$ Wald test $\mathrm{p}<0.05 ;$ †† Wald test $<0.01$; $\dagger \dagger \dagger$ Wald test $<0.001$.

Note: Adjusted by age and country. 
Table 4. Multivariate associations between the dependent variables and the socio-economic and household living arrangements indicators.

Women 65-85 years old. Adjusted odds ratios (aOR) and 95\% confidence intervals (CI). Survey of Health, Ageing and Retirement in Europe, 2004.

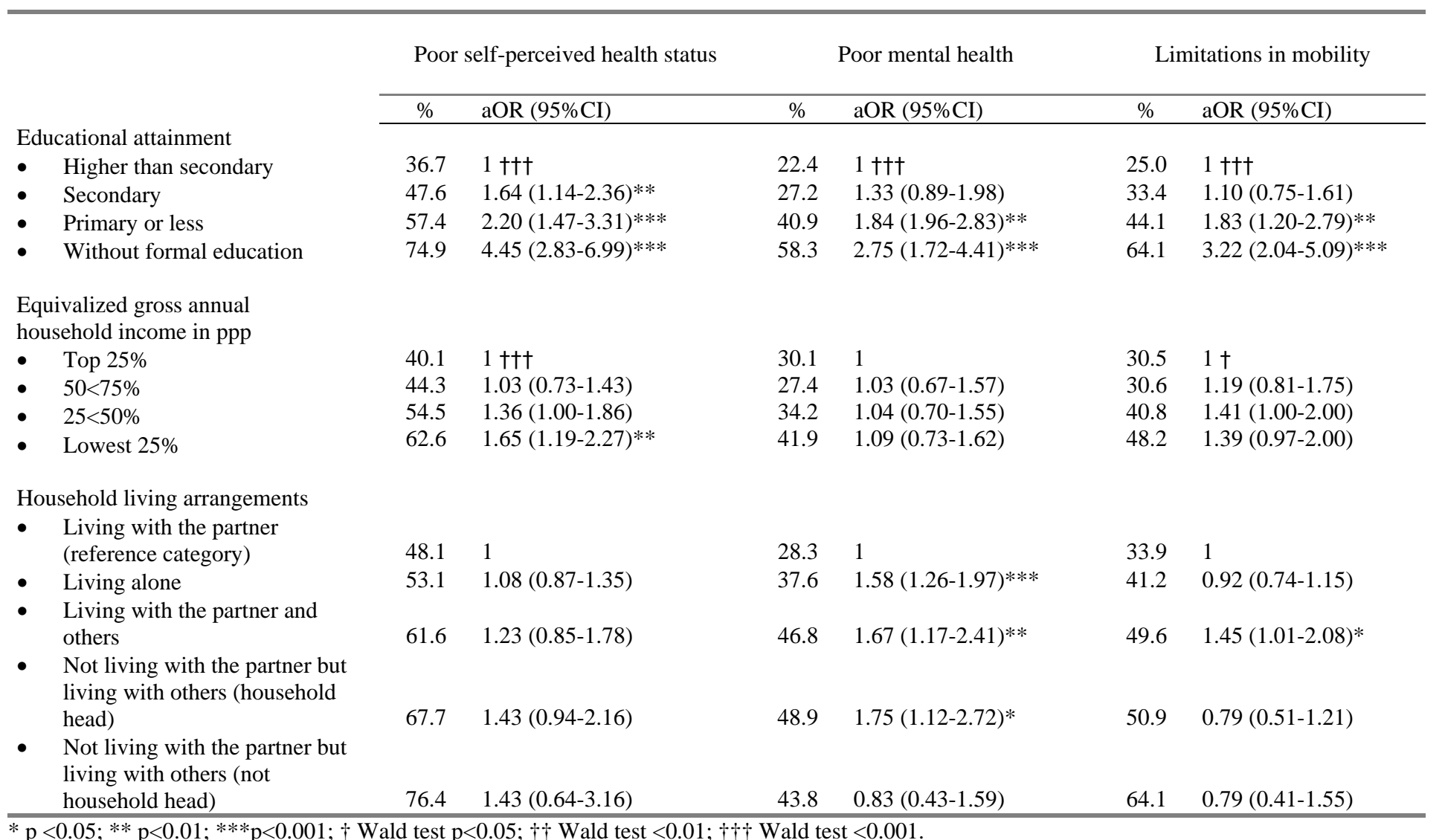

Note: Adjusted by age and country. 


\section{DISCUSSION}

Whereas traditionally literature about the relationship of living arrangements and socioeconomic position with health have developed in parallel, this study shows the importance of simultaneously considering both dimensions when studying health inequalities among the elderly. The main findings can be summarized as follows: first, and as is the case also in young people, health status among women was poorer than among men for the three health indicators analysed, although differences were lower for self-rated health status. Second, in both sexes educational attainment was negatively related to poor health with a gradient being found. Finally, the association between living arrangements and health differed by gender and was primarily related to poor mental health status.

\section{Gender differences in health status}

Our results show that older Western European women have poorer health than their male counterparts. On the other hand, as has been reported previously, elderly women's poor outcomes in functional and mental health co-existed with a smaller gender difference in selfperceived health [42]. These different gender patterns depending on the health indicator analyzed, as well as the differences in factors associated with each of them point out the importance of examining different health indicators in trying to fully understand the complexity of inequalities in health [43].

\section{Gender differences in social factors related to health status}

As in other studies, health inequalities related to the socio-economic position were confirmed among both men and women using educational attainment as socio-economic indicator [4]. There was a social gradient in which the probability of suffering from poor self-perceived health, poor mental health and limitations in mobility, arm function and fine motor function 
decreased with higher educational levels. Our results are partially consistent with those of Grundy and Slogget that concluded that the best combination of variables for investigating health inequalities among the elderly was educational qualifications or occupational social class paired with a deprivation indicator [18]. Unfortunately, not enough information on deprivation was available in the SHARE dataset. On the other hand, occupational social class was not used as an indicator of socioeconomic position because, contrary to the sample in Grundy and Slogget's study that included people over 50, our study sample was restricted to people over 64 out of the labour market.

Living arrangements were primarily related to mental health status and the pattern of associations differed by gender. Although most studies about living arrangements and health have been based on physical indicators, our findings stress the importance of also considering mental health status. These results are not consistent with those of Liang et al. who found that depressive symptoms were not significantly associated with living arrangements in a sample of community-residing older Americans [44]. Although differences attributable to social and cultural contexts cannot be ruled out, that study did not separate the analysis by sex, an additional factor that could explain the contradictory results.

In interpreting the associations found it should be taken into account that the linkages between health and living arrangements are very likely to be reciprocal. Whereas among men living alone was not associated with any health indicator, women living alone were more likely to report poor mental health status. It has been pointed out that the likelihood of entering residential care is greater for the divorced, widowed and those never married than for married people [20]. Accordingly, it can be expected that older people living alone in the community is a selection of healthier people. Actually, living alone was not associated either with poor self-perceived health status or with limitations in mobility. The positive relationship found with poor mental status among women is consistent with the role played by the level of 
social support as a strong mediator of the impact of household living arrangements on mental health among females [45][46].

In both sexes, those not living with the partner but living with others and being the household head were more likely to report poor mental health status. It is reasonable to think that among people that define themselves as the household head, burden derived from being responsible for others - for example, dependant children or other adults - is related to poor mental health status and not the reverse whereby living with others and being the household head in a family unit with no partner and other people is the result of poor mental health status. Different gender patterns were found for those people with no partner but living with others and not being the household head. Whereas men in this situation were more likely to report poor mental health status, among women there was no association with poor mental health. The persistence of gender roles in older ages may be responsible for this association. It could be that men were more likely to live with their children because of poor mental health status, whereas among women health would not determine this situation. Still, this is mere speculation and deserves further research. Literature about living arrangements uses heterogeneous categorisations of household composition but it does not consider the difference between being the household head or not that was taken into account in the present study and seems to play an important role [44-47].

Whereas living with the partner and others was not associated with health status among men, women in this situation were more likely to report poor mental health status and limitations in mobility. Although a reverse causation effect cannot be ruled out, these findings can also be interpreted as the result of gender inequalities in the distribution of domestic tasks. It has been reported that among younger people married or cohabiting, risk of poor health status increases with increasing household size [48-50]. Our results are consistent with those 
findings. Unfortunately, additional information about domestic burden was not available in the SHARE dataset.

\section{Limitations}

One of the limitations of this study is related to its cross-sectional design, a fact that prevents us from determining the causal direction. For example, as mentioned before, the relationship between living arrangements and health is likely to be reciprocal. However, we have provided some possible explanations for both causality directions depending on the specific living arrangement and gender.

Another limitation is derived from the nature of the sample. Whereas in SHARE it is stated that it was desirable to collect information about individuals living in institutions, Austria, France, Italy and Switzerland were not able to provide this [3]. In order to make country samples more comparable, and as done in most studies about inequalities in health among the elderly, we restricted the study sample to community-residing people. This may be biasing the results in the sense that, as women are more likely to become widows and then less likely to have a spouse to care for them when disabilities appear in old age, females have a higher probability of being excluded from the sample due to their higher institutionalization rates [2][42]. It would be expected that less healthy women would be excluded from our study and yet there was still an excess of female morbidity for the three health indicators analysed.

\section{Conclusion}

This study has evidenced the importance of considering indicators of socio-economic position and household living arrangements simultaneously when examining the health of older people. Moreover, it has pointed out the need to examine various health indicators in order to fully understand inequalities in health among the elderly. Further work is needed to uncover the 
mechanisms explaining how household workload of the elderly (resulting from their household living arrangements, living standards and family support from outside the household) is related to health. More research is also needed on the best indicators of socioeconomic position to be used among the elderly and the potential different meaning depending on gender. In this research both men and women should be included.

\section{What this paper adds}

Although gender and socioeconomic inequalities in health have been extensively documented, few studies about health inequalities have been carried out among the elderly.

This study shows that gender and socioeconomic inequalities in health persist among the elderly. The association between household living arrangements and health status depends on gender and is primarily related to mental health.

An integrated approach to socioeconomic inequalities, simultaneously includying indicators of household living standards and living arrangements is needed both in the research of inequalities in health as well as in social and health policies addressed to the elderly. 


\section{Acknowledgments:}

Study partially financed by a pre-doctoral grant of the Spanish Government to do my $\mathrm{PhD}$ at Pompeu Fabra University (AP2003-0816). Thanks to Carme Borrell and Carles Muntaner for their comments and suggestions.

This paper uses data from the early release 1 of SHARE 2004. This release is preliminary and may contain errors that will be corrected in later releases. The SHARE data collection has been primarily funded by the European Commission through the $5^{\text {th }}$ framework programme (project QLK6-CT-2001-00360 in the thematic programme Quality of Life). Additional funding came from the US National Institute on Ageing (U01A609740-13S2, P01 AG005842, P01 AG005842, P01 AG08291, P30 AG12815, Y1-AG-4553-01 and OGHA 04064). Data collection in Austria (through the Austrian Science Foundation, FWF), Belgium (through BBW/OFES/UFES) was nationally funded. The SHARE data set is introduced in Börsch-Supan et al.(2005); methodological details are contained in Börsch-Supan and Jürges (2005). 


\section{REFERENCES}

1. Bengtson V, Lowenstein A (eds.). Global Aging and Challenges to Families. Aldine Gruyter, New York, 2003.

2. United Nations. Living Arrangements of Older Persons Around the World. United Nations Department of Economic and Social Affairs. Population Division. ST/ESA/SER.A/240, 2005.

3. Börsh-Supan A (coord), Brugiavini A, Jürges H, et al. Health, Aging and Retirement in Europe. First Results from the Survey of Health, Aging and Retirement in Europe. Mannheim Research Institute for the Economics of Aging (MEA), 2005.

4. Huisman M, Kunst A, Mackenbach P. Socioeconomic inequalities in morbidity among the elderly: a European overview. Soc Sci Med. 2003;57:861-873.

5. Fox A, Goldblatt P, Jones D. Social class mortality differentials: artefact, selection or life circumstances?. J Epidemiol Community Health. 1985;39:1-8.

6. Arber S, Ginn J. Gender and inequalities in health in later life. Soc Sci Med. 1993;38:1257-1278.

7. Arber S, Ginn J. Health and illness in later life. In: Field D, and Taylor S. Sociological perspectives on health, illness and health care. Oxford: Blackwell Science 1998:134152.

8. Thorslund M, Lundberg O. Health and inequalities among the oldest old. J Aging Health. 1994;6:51-69.

9. Marmot M, Shipley M. Do socio-economic differences in mortality persist after retirement? 25 years follow up of civil servants from the first Whitehall Study. $\mathrm{Br}$ Med J. 1996; 313:1177-1180.

10. Dahl E, Birkelund E. Health inequalities in later life in a social democratic welfare state. Soc Sci Med. 1997; 44(6):871-881. 
11. Rahkonen O, Takala P. Social class differences in health and functional disability among older men and women. Int J Health Serv. 1998;28(3):511-24.

12. Mostafa G, van Ginneken J. Trends in and determinants of mortality in the elderly population of Matlab, Bangladesh. Soc Sci Med. 2000; 50:763-771.

13. Borrell C, Ferrando J. Desigualdades en salud en la población anciana. JANO. 2003; 64 (extra April):25-33.

14. Beckett, M. Converging Health Inequalities in Later Life - an Artifact of Mortality Selection? J Health Soc Behav. 2000; 41 (March):106-119.

15. Avlund K, Holstein B, Osler $M$ et al. Social position and health in old age : the relevance of different indicators of social position. Scand J Public Health. 2003;31:126-136.

16. Grundy E, Holt G. The socieconomic status of older adults: How should we measure it in studies of health inequalities? J Epidemiol Community Health. 2001;55:895-904.

17. Towsend P, Whitehead M, Davidson N. Inequalities in health: The Black Report and the Health Divide, New Edition. London: Penguin Books, 1992.

18. Grundy E, Slogget A. Health inequalities in the older population: the role of personal capital, social resources and socio-economic circumstances. Soc Sci Med. 2003;56:935-947.

19. Macintyre S. The patterning of health by social position in the contemporary Britain: Directions for sociological research. Soc Sci Med. 1986;23:393-415.

20. Sorlie P, Backlund E, Keller B. US mortality by economic, demographic and social characteristics: The National Longitudinal Mortality Study. Am J Public Health. 1995;85:949-956.

21. Lund R, Due P, Moduig J, et al. Cohabitation and marital status as predictors of mortality-an eight year follow-up study. Soc Sci Med. 2002;55:673-679. 
22. Zimmer Z. A further discussion on revisiting the classification of household composition among elderly people. J Cross Cult Gerontol. 2001;18:247-250.

23. Henderson A, Scott R, Kay D. The elderly who live alone: their mental health and social relationships. Aust NZ J Psychiatr. 1986;20:202-09.

24. Michael Y, Berkman L, Colditz G, Kawachi I. Living Arrangements, Social Integration, and Change in Functional Health Status. Am $J$ Epidemiol. 2001;153(2):123-131.

25. Anson O. Living arrangements and women’s health. Soc Sci Med. 1988;26:201-208.

26. Magaziner J, Cadigan D, Hebel J, et al. Health and living arrangements among older women: does living alone increase the risk of illness?. J Gerontol. 1988;43:M127-33.

27. Sarwari A, Fredman L, Langenberg P, et al. Prospective study on the relation between living arrangements and change in functional health status of elderly women. Am $J$ Epidemiol. 1998;147:370-8.

28. Börsch-Supan A, Jürgens H (eds.). The Survey of Health, Aging and Retirement in Europe-Methodology. Mannheim Research Institute for the Economics of Aging (MEA). 2005.

29. Bond J, Coleman P, Peace S. Ageing in society. An introduction to social gerontology. Second Edition. British Society of Gerontology. 1993.

30. Mossey J, Shapiro E. Self-rated health: a predictor of mortality among the elderly. Am J Public Health. 1982;72:800-8.

31. Ferraro K, Farmer M. Double Jeopardy, Aging as Leveler, or Persistant Health Inequality? A Longitudinal Analysis of White and Black Americans. J Gerontol. 1996; 51B:S319-28. 
32. Copeland J, Dewey M, Griffiths-Jones H. Computerised psychiatric diagnostic system and case nomenclature for elderly subjects: GNS and AGECAT. Psychol Med. 1986;16:89-99.

33. Radloff L. The CES-D scale: a self-report depression scale for research in the general population. Applied Psychological Measurement. 1977;1:385-401.

34. Prince M, Reischies F, Beekman T, et al. Development of the EURO-D scale - A European Union initiative to compare symptoms of depression in 14 European centres. Br J Psychiatry. 1999;174:330-338.

35. Beekman A, Copeland J, Prince M. Review of community prevalence of depression in later life. Br J Psychiatry. 1999;174:307-11.

36. Braam A, Prince M, Beekman A et al. Physical health and depressive symptoms in older Europeans. Results from EURODEP. Br J Psychiatry. 2005;187:35-42.

37. Copeland J, Hooijer C, Jordan A et al. Depression in Europe: Geographical distribution among older people. Br J Psychiatry. 1999;174:312-21.

38. Prince M, Beekman A, Fuhrer R et al., Depression symptoms in later-life assessed using the EURO-D scale. Effect of age, gender and mental health status in 14 European centres. Br J Psychiatry. 1999;174:339-45.

39. Brugiavini A, Croda E, Rainato R, et al. Generated Income Variables. (Short) Memo. www.share-project.org (accessed 12 October 2006).

40. SHARE Project. Accesible at: http://share-project.org.

41. Hosmer D, Lemeshow S. Applied Logistic Regression (2 ${ }^{\text {nd }}$ Edition). John Wiley \& Sons, New York, 2000.

42. Arber S, Cooper H. Gender differences in health in later life: the new paradox?. Soc Sci Med. 1999;48(1):61-76. 
43. Macintyre S, Kunt H, Sweeting H. Gender differences in health. Are things really as simple as they seem?. Soc Sci Med. 1996;42:617-624.

44. Liang J, Winchester J, Krause $\mathrm{N}$ et al. Health and living arrangements among older americans: Does marriage matter? J Aging Health. 2005;17:305.

45. Joutsenniemi K. et al. Living arrangements and mental health in Finland. J Epidemiol Community Health. 2006;60:468-475.

46. Hughes M, Waite L. Health in Household Context: Living Arrangements and Health in Late Middle Age. J Health Soc Beha. 2002;43(1):1-21.

47. Grundy E, Mayer D, Young $\mathrm{H}$ et al. Living arrangements and place of death of older people with cancer in England and Wales: a record linkage study. $\mathrm{Br} J$ Cancer. 2004;91:907-12.

48. Artazcoz L, Borrell C, Benach J. Gender inequalities in health among workers: the relation with family demands. J Epidemiol Community Health. 2001;55:639-47.

49. Borrell C, Muntaner C, Benach J et al. Social class and self-reported health status among men and women: what is the role of work organization, household material standards and household labour. Soc Sci Med. 2004;58:1869-87.

50. Artazcoz L, Arieta L, Borrell C et al. Combining job and family demands and being unhealthy: What are the differences between men and women? Eur J Public Health. 2004;14:43-48. 